FE DER A L EN ER G Y MA N A G E M N T PROG R A M

\title{
Innovative Utility Partnership at Fort Lewis, Washington
}

Unique partnership showcases the benefits of collaborative financing to meet Federal energy efficiency goals

\section{Overview}

As a result of an integrated resource assessment conducted by Pacific Northwest National

Laboratory in 1990, the U.S. Department of Energy's Federal Energy Management Program (FEMP) developed an innovative, three-way partnership to finance upgrading the U.S. Army post at Fort Lewis, Washington, with energy-efficient electrical equipment. The partnership consisted of the U.S. Army Forces Command/Fort Lewis, Tacoma Public Utilities (TPU), and the Bonneville Power Administration (BPA).

The \$11 million Fort Lewis project is unique and one of FEMP's largest. In the partnership agreement, TPU finances all the installation costs and procures and pays the energy service contractor. During a 5 -year period, the contractor conducts detailed audits and installs equipment.

In December 1992, TPU selected EAU Cogenex as the energy service company contractor to design, install, and verify all feasible electric energy conservation measures for the post's buildings. Cogenex will initially pay all installation and equipment costs. TPU will reimburse $85 \%$ of these costs when construction is complete and the rest after the energy savings are verified. At this time, Fort Lewis will reimburse TPU for $15 \%$ of the installation costs as each phase is completed. TPU will acquire the other $85 \%$ by selling unused energy to BPA. TPU guarantees an energy saving, and BPA buys saved energy each year.

For an initial investment of less than $\$ 1.8$ million, Fort Lewis will reduce its annual energy costs by more than $\$ 700,000$.

\section{Background}

Fort Lewis is located south of Tacoma, Washington, and consumes more than 220 million kilowatt-hours $(\mathrm{kWh})$ of electricity annually. Its 4,200 buildingssingle- and multifamily homes, concrete barracks, and office and administration buildings-account for $85 \%$ of its electricity use.

Most upgrades will be for lighting, but many motors will be replaced with energy-efficient ones. Improved controls and timers will be installed for more intelligent control of the motors and pumps, which will increase efficiency and save electricity. Transformers will be replaced with more energy-efficient units to reduce transmission losses and improve power factors.

\section{Project summary}

Using the contract between Fort Lewis and TPU greatly simplified this large and otherwise complex project. TPU manages the subcontract with Cogenex, and Cogenex manages the subcontracts with local electricians. This arrangement improves administrative efficiencies and reduces Fort Lewis's administrative costs.

The lighting and motor retrofits will save more than 27 million $\mathrm{kWh}$ (about $\$ 700,000$ ) per year.

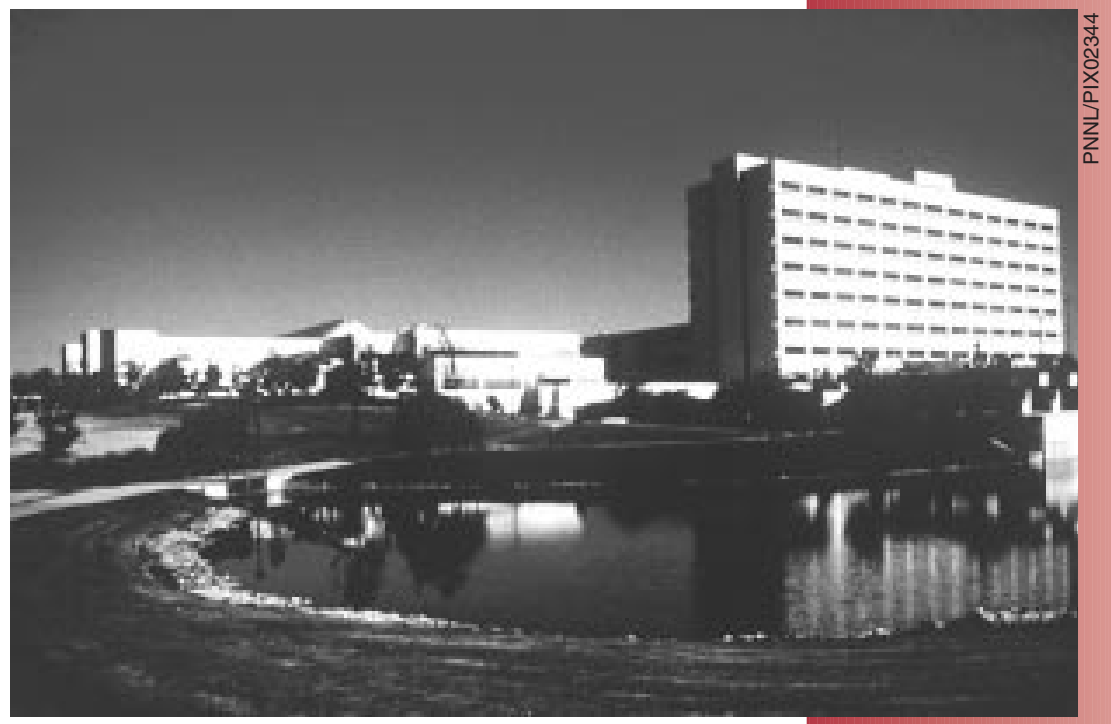

Madigan Army Medical Center is one of the buildings at Fort Lewis that received energy efficiency improvements.

\section{Benefits of utility contracting}

The contract at Fort Lewis was designed to replace or upgrade aging equipment, reduce utility and operations and maintenance costs, and help the U.S. Department of Defense meet its energy-reduction goals.

The energy saved at Fort Lewis will provide Tacoma and the region with surplus hydro-power, which is economical and helps reduce emissions of carbon

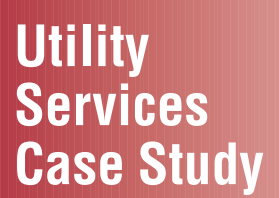

U.S. Department of Energy

Office of Energy Efficiency and Renewable Energy 
dioxide, carbon monoxide, nitrogen oxides, sulfur oxides, and hydrocarbons.

\section{Lessons learned}

\section{Working with utilities}

Fort Lewis is a prime example of what a Federal site can accomplish when it works with local utilities.

Because the utility manages the project, procedures for procurement, installation, and other processes are greatly simplified.

\section{Managing the unexpected}

Additionally, during the development and negotiation stages, several changes occurred that were not covered in the original contract. For example, more than 700 buildings were demolished because of age, deterioration, and Army downsizing, so the contractor could not include them in its proposal. In addition, new requirements arose for treating ballasts and fluorescent lamps as hazardous waste; new procedures had to be created to handle this problem. Asbestos surveys had to be conducted for all buildings before the contractors could enter them. And there were other repairs that were not covered by the contract. All these problems were resolved, and the contract went forward.

\section{Looking ahead}

All parties will benefit from this unique partnership:

- Fort Lewis will receive millions of dollars in energy-efficient technologies but will pay only $15 \%$ of the cost. It will use approximately $10 \%$ less electricity, meanwhile maintenance costs will also be lower.

- The reduction in electricity consumption allows the utilities to defer the construction of new generating facilities.

\section{For More Information}

FEMP Help Desk:

(800) DOE-EREC (363-3732)

Fax: (202) 586-3000

Internet: http:/ / www.eren.doe.gov/femp

Brad Gustafson

Utility Services Program Manager

DOE FEMP

(202) 586-2204

For more information about the project, contact:

Brett Langlois

Fort Lewis Army Post

(253) 967-2837

\section{Energy savings from selecting energy-efficient motors over standard motors*}
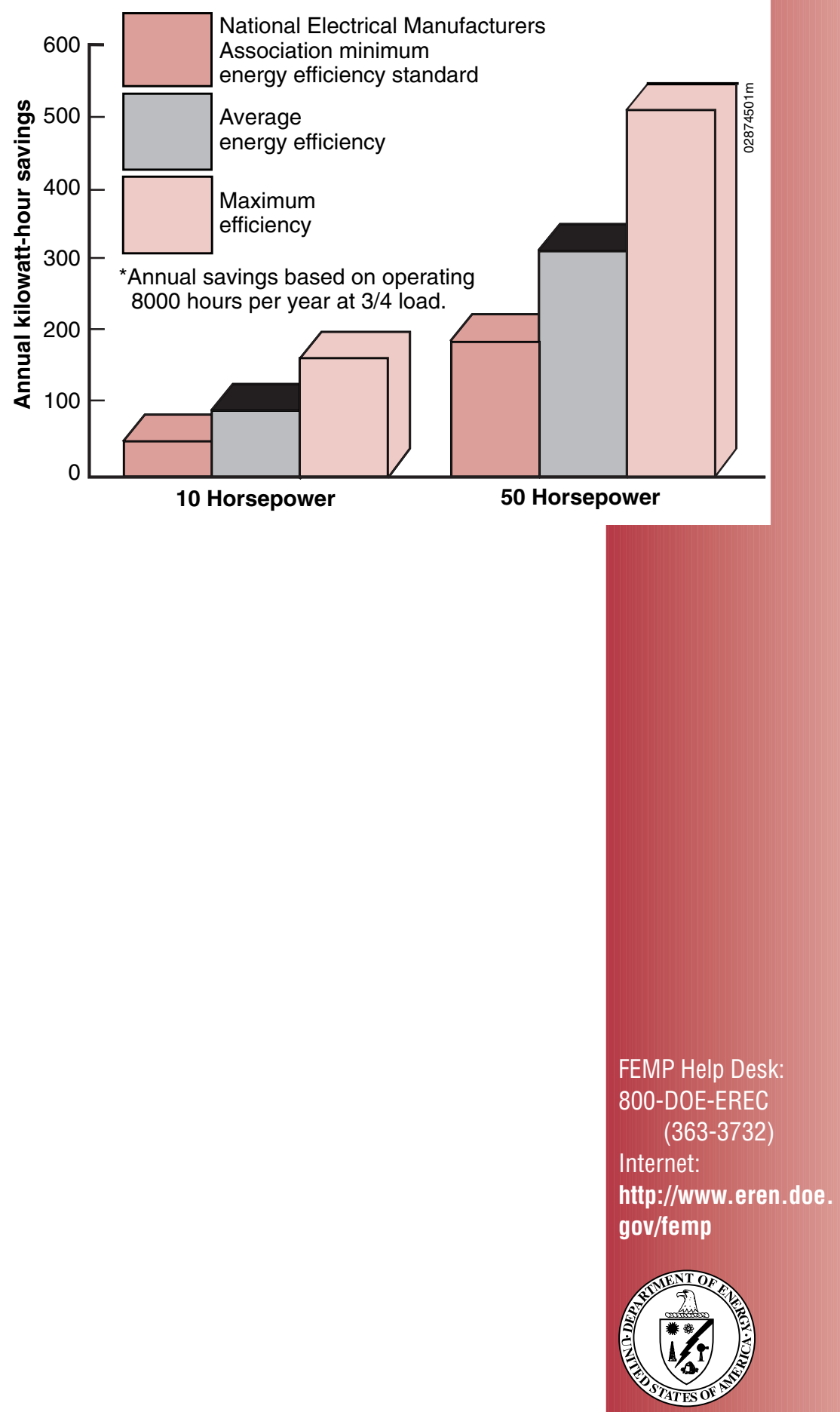

Produced for the

U.S. Department

of Energy by the

National Renewable

Energy Laboratory,

a DOE national

laboratory

DOE/GO-102000-1100 July 2000 